\title{
Resistência de Genótipos de Tomateiro a um Isolado de Geminivírus do Cinturão Verde de Campinas, São Paulo
}

\author{
Evandro S. Matos ${ }^{1 *}$, Walter J. Siqueira ${ }^{2}$, André L. Lourenção ${ }^{2 * *}$, Arlete M.T. Melo ${ }^{2}$, Haiko E. Sawazaki ${ }^{2}$, \\ José Alberto C. Souza-Dias ${ }^{2} \&$ Addolorata Colariccio $^{3}$
}

\author{
${ }^{1}$ Syngenta Seeds Ltda., Avenida das Nações Unidas, 18001, CEP 04795-900, São Paulo, SP, e-mail: \\ evandro.matos@syngenta.com; '2Instituto Agronômico (IAC), Cx. Postal 28, CEP 13001-970, Campinas, SP; \\ ${ }^{3}$ Instituto Biológico, Cx. Postal 7119, CEP 01064-970, São Paulo, SP
}

(Aceito para publicação em 13/02/2003)

Autor para correspondência: Walter J. Siqueira

MATOS, E.S., SIQUEIRA, W.J., LOURENÇÃO, A.L., MELO, A.M.T., SAWAZAKI, H.E., SOUZA-DIAS, J.A.C. \& COLARICCIO, A. Resistência de genótipos de tomateiro a um isolado de geminivírus do cinturão verde de Campinas, São Paulo. Fitopatologia Brasileira 28:159-165. 2003.

\section{RESUMO}

Plantas de tomateiro (Lycopersicon esculentum) apresentando sintomas de amarelecimento do limbo foliar principalmente nas nervuras, redução de crescimento e distorções foliares foram coletadas em lavouras do cinturão verde de Campinas, São Paulo, e mantidas no Centro Experimental de Campinas (IAC), para utilização em experimentos de avaliação de resistência de genótipos à virose. A partir de análises moleculares, o vírus foi identificado como Tomato yellow vein streak virus (TYVSV). Foram feitas avaliações em campo (infecção natural) e em telado (infecção natural e controlada), usando-se diversos genótipos, abrangendo cultivares, híbridos, linhagens e populações, além de espécies selvagens de tomateiro. Alguns dos genótipos e híbridos contêm o gene de resistência Ty-1. Em campo, destacou-se o híbrido 'BX 1016158' com as menores incidências de doença. Em telado (infecção natural), híbridos interespecíficos de $L$. esculentum x L. peruvianum, e a linhagem PI 134417 (L. hirsutum) mostraram-se os mais resistentes ao isolado. O método de avaliação precoce em telado (infecção controlada) mostrou-se adequado para discriminar genótipos resistentes ao isolado. Por meio desse método, constatou-se a resistência das linhagens 'LA 444-1' (L. peruvianum), $\mathrm{F}_{4}$ (TySw5) e a série IAC 14-2, e dos híbridos 'Franco' e BX1653088 ('Densus'), os quais receberam notas próximas de um ou não apresentaram sintomas.

Palavras-chave adicionais: Lycopersicon spp., Geminiviridae, Tomato yellow vein streak virus, Bemisia tabaci biótipo B.

\begin{abstract}
Resistance of tomato genotypes to an isolate of geminivirus from green belt of Campinas, São Paulo, Brazil

Tomato (Lycopersicon esculentum) plant showing symptoms attributed to geminivirus were collected from crops of the green belt of Campinas, SP. The symptoms consisted of leaf yellowing, especially along the veins, leaf distortion and reduced plant growth. A virus isolate was maintained in tomato plants by whiteflies transmission at the Experimental Center of Instituto Agronômico in Campinas. Molecular tests were performed with the virus, which showed to be Tomato yellow vein streak virus (TYVSV). Evaluations of tomato resistance were done under field (natural infections) and screen house conditions (natural and controlled infections) using genotypes of diverse origins, comprising cultivars, hybrids, breeding

lines, populations and wild tomato species. The evaluated material included experimental genotypes and hybrids carrying the gene for vertical resistance, $T y-1$. In the field, the evaluations pointed to the hybrid 'BX 1016158' as having the the lowest disease infection rates. In screen house conditions, the interspecific hybrids of $L$. esculentum $\mathrm{x}$ L. peruvianum, and the access PI 134417 of L. hirsutum showed the highest resistance to the virus. Another screen house experiment used a method of early testing for resistance of tomato genotypes to geminivirus. This method proved to be adequate for discrimination of genotypes, found resistance in the L. peruvianum access LA 444-1, in the IAC 14-2 series, in the F4 line TySw5, and in the hybrids 'Franco' and BX 1653088 ('Densus'), with ratings close to absence of symptoms.
\end{abstract}

\section{INTRODUÇÃO}

No Brasil e demais países produtores de tomate (Lycopersicon esculentum Mill.), seu cultivo durante o ano inteiro propicia condições favoráveis ao surgimento de doenças causadas por fungos, bactérias e, principalmente por

\footnotetext{
*Bolsista da FAPESP

**Bolsista do CNPq
}

vírus. Dentre elas, as causadas por geminivírus, transmitidas por moscas-brancas do complexo Bemisia tabaci (Genn.) podem ser consideradas como limitantes à produção comercial do tomate (Brown et al., 1995a). Os geminivírus constituem a família Geminiviridae, composta pelos gêneros Mastrevirus, Curtovirus, Begomovirus e Topocuvirus (Rybicki, 1994; Timmermans et al., 1994; Palmer \& Rybicki, 1998; Van Regenmortel et al., 2000). As espécies de vírus pertencentes 
ao gênero Begomovirus possuem genoma com uma ou duas moléculas de DNA circular de fita simples, como a espécie Tomato yellow vein streak virus (TYVSV). Os demais gêneros são compostos por vírus com genoma contendo um único componente.

Tomateiros infetados por geminivírus apresentam, geralmente, amarelecimento na base dos folíolos e clareamento de nervuras, evoluindo para mosaico amarelo. Estes sintomas se generalizam por toda a planta, seguidos de rugosidade, redução de tamanho e enrolamento dos bordos da folha. A planta apresenta redução da floração, paralisação no crescimento, com conseqüente perda na produção, principalmente se a infecção das plantas ocorrer nos estádios iniciais de desenvolvimento (Ribeiro et al., 1994; Rezende et al., 1996).

Nenhuma estratégia de controle, quando utilizada isoladamente, tem demonstrado ser efetiva para as doenças causadas por geminivírus. O controle químico das moscasbrancas é prejudicado pela constante migração de grandes populações do inseto de lavouras mais velhas para as mais novas, e também devido à possibilidade de se tornarem resistentes aos inseticidas (Harrison, 1985; Gerling, 1990). Portanto, as medidas de controle devem enfatizar a eliminação ou a redução das fontes de vírus, a redução da população do inseto vetor existente e, finalmente, alterações do nível de suscetibilidade do hospedeiro. Nesta última linha, pesquisas para identificação de fontes de resistência começaram por volta de 1970 (Laterrot, 1993; 1995). A espécie selvagem Lycopersicon chilense Dun., fonte do gene $T y$-1, engloba diversas linhagens com alto nível de resistência a isolados de geminivírus da França, Israel, Flórida (EUA) e das Américas (Zakay et al., 1991). Atualmente, muitas introgressões gênicas em cultivares vêm sendo realizadas com o gene $T y$-1, originário da linhagem LA 1969 (Giordano et al., 1994). Este gene interfere na proteína viral responsável pela circulação do vírus na planta (movimento célula a célula), sendo mais eficiente em condições de baixo inóculo (Laterrot, 1993; Giordano et al., 1994; Michelson et al., 1994; Zamir et al., 1994). Segundo Kasrawi et al. (1988), linhagens de L. peruvianum f. humifusum C. H. Mull. e de L. peruvianum (L.) Mill. exibiram altos níveis de resistência a Tomato yellow leaf curl virus (TYLCV). De acordo com esses autores, a herança da tolerância presente em uma das linhagens (PI 126935) de L. peruvianum é controlada por cinco genes recessivos. Em 1988, em Israel, já havia sido liberada cultivar de tomateiro tolerante a TYLCV derivada dessa PI (Pilowsky \& Cohen, 1990). Em linhagens de L. pimpinellifolium (Jusl.) Mill. , a tolerância a TYLCV tem mostrado diferentes tipos de herança, como monogênica incompleta, monogênica dominante e poligênica (Pilowsky \& Cohen, 1974). Outras espécies de tomateiro, como L. cheesmanii ssp. minor (Hook) C. H. Mull. e L. hirsutum Humb. \& Bonpl. possuem herança do tipo monogênica recessiva e mais do que um gene dominante, respectivamente (Kasrawi et al., 1988).

A presente pesquisa teve por objetivo avaliar a resis- tência de genótipos de tomateiro de diferentes origens, abrangendo cultivares e híbridos comerciais, linhagens e populações derivadas de espécies selvagens, materiais segregantes para o gene $T y-1$ e outros, para um isolado de geminivírus coletado no cinturão verde de Campinas, SP.

\section{MATERIAL E MÉTODOS}

\section{Obtenção e caracterização do isolado de geminivírus}

No segundo semestre de 2000, algumas lavouras de tomate do cinturão verde de Campinas, apresentaram surtos populacionais de mosca-branca juntamente com os sintomas típicos de geminivírus ou mais precisamente, sintomas de risca amarela nas nervuras. Em visita a algumas destas lavouras, verificou-se que as moscas-brancas pertenciam ao biótipo B de $B$. tabaci em função dos sintomas de prateamento foliar observado em cucurbitáceas plantadas no perímetro das lavouras (Brown et al., 1995b). Nesses locais foram realizadas algumas coletas de material vegetal de tomate infetado (cultivar híbrido Carmen), apresentando sintomas típicos da doença.

Coletaram-se ramos e brotos apicais de plantas adultas; também se coletaram plantas novas com raiz, as quais foram transplantadas em vasos plásticos. Os ramos apicais e os ramos axilares ou laterais foram plantados em bandeja de isopor com 60 células, contendo substrato Plantmax, e regados diariamente, visando seu enraizamento. As folhas adultas com sintomas de amarelecimento e deformações foram destacadas e enxertadas por meio de garfagem em plantas sadias de tomateiro, cultivar IPA-6, com 50 dias de idade. Após a enxertia, as folhas foram acondicionadas em câmaras confeccionadas por pequenos sacos plásticos para evitar o ressecamento. Juntamente com as etapas de manutenção e multiplicação do isolado obtido, procedeu-se a sua caracterização molecular, seqüenciando-se o fragmento (amplicon) obtido através de PCR com o par de primers degenerados PAC1v1978/PAV1c715, que amplifica parte do gene rep (ORF AC1), a região comum (CR), e parte do gene cp (ORF AV1) (Rojas et al., 1993).

\section{Criação de moscas-brancas virulíferas}

Plantas adultas de tomateiro com sintomas característicos de infecção por geminivírus (comprovada após reação de PCR), foram colocadas em insetário do setor de Entomologia do IAC para iniciar o processo de criação de moscas-brancas. Para a colonização em plantas de tomateiro, foram colocadas no referido insetário cerca de 10.000 moscasbrancas de $B$. tabaci biótipo $\mathrm{B}$, de cuja criação várias amostras haviam sido identificadas previamente pela Dra. Judith K. Brown, Universidade do Arizona, EUA.

Após sete dias de alimentação no tomateiro, as moscasbrancas foram utilizadas nos experimentos de avaliação de resistência ao geminivírus, uma vez que o período médio de latência é de apenas 6-12 h antes da transmissão (Rosell et al., 1999). Para manutenção de moscas-brancas virulíferas no insetário, foram repostas regularmente plantas novas sadias 
ao lado de plantas de tomateiro com sintomas e colonizadas pela mosca-branca.

\section{Avaliação da resistência em campo}

Foram avaliados quinze genótipos, abrangendo linhagens, cultivares e híbridos pertencentes ao banco de germoplasma de tomate do IAC, empregando-se como controle suscetível a cultivar IPA-6 (Tabela 1). Os genótipos testados da série TPN, TWN e IAC S4 são linhagens que vêm sendo selecionadas há pelo menos cinco anos em condições de campo para resistência a diferentes espécies de tospovírus (Lourenção et al., 2001), mas sem informações sobre o comportamento em relação a geminivírus.

O delineamento experimental usado foi de blocos ao acaso, com cinco repetições por tratamento. Cada parcela foi composta de duas linhas de $3 \mathrm{~m}$ de comprimento, com espaçamento entre plantas de $0,5 \mathrm{~m}$ e $1 \mathrm{~m}$ entre linhas, perfazendo um total de 14 plantas por parcela. Aos 35 e 55 dias após o transplante das mudas para o campo, procedeu-se à avaliação da incidência da doença através da contagem de plantas sintomáticas nas duas linhas de cada parcela, para obtenção da porcentagem de plantas com sintomas.

\section{Avaliação da resistência em telado}

Neste experimento, analisou-se a reação de genótipos de tomateiro quando germinados na presença de moscasbrancas virulíferas. Foram semeados em bandejas de isopor doze genótipos, dentre cultivares, espécies selvagens, populações segregantes com o gene $T y$ - 1 e gerações de cruzamentos interespecíficos (Tabela 2). Após a germinação das sementes, as bandejas ficaram dispostas no interior de telado contendo, ao redor, plantas de tomateiro com sintomas de geminivírus infestadas por moscas-brancas. Essa condição foi mantida até os 30 dias após a semeadura, quando foram transplantadas para vasos. Este procedimento, baseado em exposição precoce, deveu-se aos trabalhos realizados por Belén Picó \& Nuez (1998), que verificaram que plantas possuidoras do gene de resistência a geminivirus Ty- 1 apresentam redução do nível de resistência quando são infestadas nos estádios iniciais de desenvolvimento com, no mínimo, dez moscas-brancas virulíferas em condições de casa de vegetação. Para cada genótipo, transplantou-se uma planta por vaso, constituindo-se a parcela. O delineamento experimental utilizado foi o inteiramente casualizado, com doze repetições por tratamento. A avaliação de sintomas de geminivírus foi realizada 30 dias após o transplante, por dois avaliadores independentes, utilizando-se uma escala de notas de 1 a 5, adaptada de Ferreira et al. (1999) e ilustrada por Matos (2001), onde 1= ausência de sintoma, 2= ligeira descoloração dos folíolos, $3=$ ligeira descoloração com início de enrugamento dos folíolos, 4= descoloração e enrugamento dos folíolos e $5=$ severa clorose e enrugamento acentuado dos folíolos.

\section{Avaliação em gaiolas}

O método empregado neste experimento foi seme- lhante ao utilizado pela Embrapa Hortaliças, em Brasília-DF (Giordano et al., 1999). Foi substituído o tubo PVC das gaiolas por garrafas plásticas transparentes, as quais possibilitam maior luminosidade às plantas, evitando seu estiolamento e permitindo melhor acompanhamento da atividade das moscasbrancas. Após colocação das gaiolas, plantas de tomateiro com 30 dias de idade foram infestadas com 15 moscas-brancas virulíferas (Belén Picó \& Nuez, 1998), sendo o período de infestação de três dias (Hunter et al., 1998). O delineamento experimental utilizado foi o inteiramente casualizado, com dez repetições por tratamento e uma planta por vaso. Após este período, as plantas foram retiradas e imediatamente pulverizadas com imidaclopride para eliminar as moscasbrancas remanescentes. Aos 28 dias após a infestação artificial, procedeu-se à avaliação utilizando-se a mesma escala de notas e critérios empregados anteriormente. Foram conduzidos dois experimentos em gaiolas, utilizando-se cultivares, linhagens, espécies selvagens e populações derivadas de cruzamentos interespecíficos e também segregando para o gene $T y-1$ (Tabela 3).

\section{Análise estatística}

Os resultados de porcentagem de plantas com sintomas (avaliação de campo) foram transformados em arco seno $\sqrt{\% / 100}$ e os de nota (avaliações em telado e em gaiolas), em $\sqrt{\mathrm{X}}$. Efetuaram-se análises de variância, sendo as médias comparadas pelo teste Tukey, a 5\% de probabilidade.

\section{RESULTADOS E DISCUSSÃO}

\section{Identificação do geminivírus}

A reação de PCR com nucleotídeos marcados por fluorescência, visualização e extração de bandas específicas em gel de eletroforese com posterior purificação, seqüenciamento e análise dos amplicons obtidos (Figura 1), permitiram concluir que o isolado coletado no cinturão verde de Campinas, SP, refere-se à espécie TYVSV, descrita por Faria et al. (1997).

\section{Avaliação da resistência em campo}

$\mathrm{Na}$ primeira avaliação, realizada aos 58 dias da semeadura, verificou-se variação acentuada entre os genótipos na manifestação da doença, com incidência variando entre 1,1 e 67,3\% (Tabela 1). Apesar da eficiência de transmissão do geminivírus pela mosca-branca (Hunter et al., 1998), a manifestação dos sintomas é variável em função das condições de ambiente e do estádio vegetativo das plantas. Não existindo barreiras consistentes à replicação e/ou movimento do vírus nas células, ocorre maior uniformidade na manifestação dos sintomas nas plantas, com o decorrer do tempo, após o início da infecção. Assim, o uso da primeira data de avaliação poderia conduzir a erros de interpretação para seleção das plantas resistentes nos estádios iniciais do estabelecimento do patógeno. Vale salientar que o critério adotado para avaliação das plantas em condições de campo, quanto à resistência ao geminivírus foi qualitativo, ou seja, presença/ 


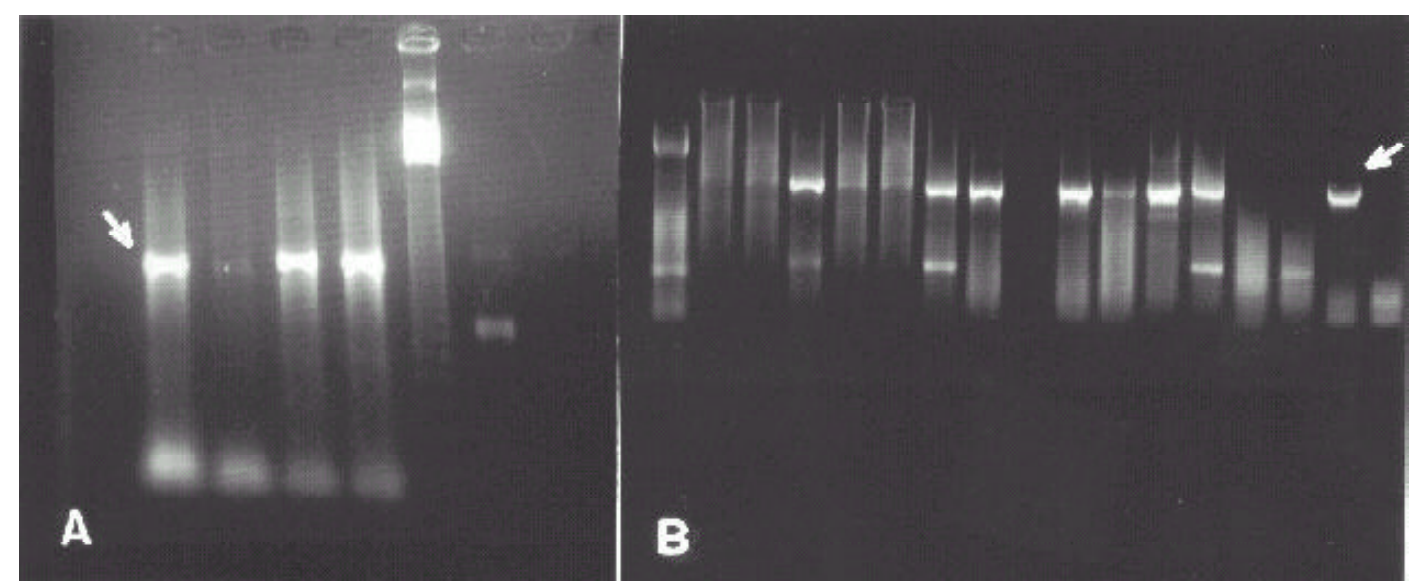

FIG. 1 - Produto de amplificação de fragmento de DNA de folhas de tomateiros (Lycopersicon esculentum) com sintomas de geminivírus, usando o par de primers PACv1978/PAV1c715, com bandas das amostras na região de 1230 pares de bases (pb). A: Ladder com incrementos de $123 \mathrm{pb}$; B: Ladder com incrementos de $100 \mathrm{pb}$.

ausência de sintomas, não importando sua severidade. Este tipo de avaliação é de certa forma fácil de ser realizado, pois permite rapidez na identificação de plantas com ou sem sintomas, embora não permita avaliar diferentes graus da reação de resistência à replicação e ao movimento do vírus na célula.

Na segunda avaliação, aos 78 dias da semeadura, notou-se menor variação nas incidências médias de plantas sintomáticas, apesar de terem ocorrido diferenças entre os genótipos testados. O nível de quase $100 \%$ de incidência na testemunha suscetível 'IPA-6', e o valor obtido para um coeficiente de variação experimental de $13,2 \%$, evidenciam a uniformidade de transmissão do geminivírus em todas as repetições do experimento. As porcentagens de plantas doentes foram altas para todos os materiais testados, nos quais as menores incidências se situaram entre 64,0 e $77,0 \%$, respectivamente para dois $\mathrm{F}_{1}$ 's (BX 1016158 e TX 414 x Rey de los Tempranos). Atualmente, não é aconselhável o lançamento de cultivar de tomateiro sem resistência a geminivírus em função de sua ampla disseminação e agressividade de ataque em lavouras comerciais distribuídas por todo o país. As cultivares Viradoro, Stevens e IPA-6, e outras linhagens apresentaram-se como suscetíveis, com incidências entre 85,2 e 99,6\%.

Deve-se salientar o incremento de plantas com sintomas da primeira para a segunda avaliação para o híbrido $F_{1}$ (BX 1016158), que foi de 1,1 para $64,1 \%$. Além deste, houve um aumento de plantas sintomáticas de 22,0 para $86,9 \%$ em F F $_{1}$ TSW10 x Kada Gigante) e de 38,9 para 85,2\% em TPN B 51099. Estes fatos demonstram a agressividade deste geminivírus quando as condições são favoráveis para o vetor e para o agente causal, o que evidencia a importância de os produtores manterem um aprimorado acompanhamento do estado fitossanitário de suas lavouras, tanto com relação aos tratos culturais e pulverizações com defensivos, quanto ao isolamento da cultura, principalmente nos primeiros 45 dias após o transplante das mudas para o campo.

\section{Avaliação da resistência em telado}

Dos resultados obtidos (Tabela 2), pode-se verificar que a linhagem PI 134417 (L. hirsutum) e os híbridos interespecíficos entre L. esculentum $\mathrm{x}$ L. peruvianum (séries IAC 14-2 e IAC 68F) mostraram grau superior de resistência, com notas médias variando entre 1,2 e 1,8, quando germinados na presença de moscas-brancas virulíferas. Com exceção das linhagens da série IAC 14-2, LA 444-1 ( $L$. peruvianum) se destacou de todos os outros genótipos testados, com relação à resistência ao isolado de geminivírus utilizado. Além disso, essa linhagem apresenta resistência a um tospovírus não identificado (Lourenção et al., 1997) e à traça-

TABELA 1 - Porcentagem média de incidência de geminivírus em três cultivares, oito linhagens e quatro híbridos $\left(\mathrm{F}_{1}\right)$ de tomateiro (Lycopersicon esculentum) em condições de campo, em duas épocas de avaliação

\begin{tabular}{llc}
\hline \hline \multirow{2}{*}{ Genótipo } & \multicolumn{2}{c}{$\begin{array}{c}\text { Incidência de plantas } \\
\text { com sintomas }{ }^{1}(\%)\end{array}$} \\
\cline { 2 - 3 } & $\mathbf{5 8 ~ d . a . g .}{ }^{2}$ & $\mathbf{7 8 ~ d . a . g .}{ }^{2}$ \\
\hline TWN 05/98 & $30,7 \mathrm{bcd}$ & $99,6 \mathrm{a}$ \\
'IPA-6' & $49,3 \mathrm{abc}$ & $99,5 \mathrm{a}$ \\
TPN B21099 & $63,3 \mathrm{a}$ & $99,5 \mathrm{a}$ \\
'Stevens' & $18,1 \mathrm{de}$ & $97,8 \mathrm{ab}$ \\
TPN B41099 & $47,9 \mathrm{abc}$ & $97,7 \mathrm{ab}$ \\
'Viradoro' & $63,5 \mathrm{a}$ & $96,2 \mathrm{ab}$ \\
IAC S4-3-18C & $41,0 \mathrm{abcd}$ & $95,5 \mathrm{ab}$ \\
IAC S4-4-16A & $52,8 \mathrm{ab}$ & $93,6 \mathrm{abc}$ \\
TPN B11099 & $67,3 \mathrm{a}$ & $89,7 \mathrm{bc}$ \\
F1(TSW10 x Kada Gigante) & $22,0 \mathrm{cde}$ & $86,9 \mathrm{bc}$ \\
TPN B31099 & $48,5 \mathrm{abc}$ & $86,8 \mathrm{bc}$ \\
TPN B51099 & $38,9 \mathrm{bcde}$ & $85,2 \mathrm{bc}$ \\
F1(TX414 x Rey de los Tempranos) & $19,6 \mathrm{de}$ & $76,9 \mathrm{~cd}$ \\
F1(BX 1016158) & $1,1 \mathrm{f}$ & $64,1 \mathrm{~d}$ \\
\hline Média & 38,2 & 90,3 \\
C.V. (\%) & 31,1 & 13,2 \\
\hline
\end{tabular}

${ }^{1}$ Médias seguidas de mesma letra na coluna não diferem significativamente entre si pelo teste Tukey a $5 \%$ de probabilidade.

${ }^{2}$ d.a.g.: dias após a germinação 
Resistência de genótipos de tomateiro a um isolado de geminivírus...

TABELA 2 - Notas médias de avaliação ${ }^{1}$ de genótipos de tomateiro (Lycopersicon esculentum) para resistência a geminivírus, com plântulas desenvolvidas na presença de moscasbrancas virulíferas, em condições de telado

\begin{tabular}{lcc}
\hline \hline Genótipo & \multicolumn{1}{c}{ Espécie } & Nota $^{2}$ \\
\hline F1(IAC S4-3-18C x TySw5) & Lycopersicon esculentum & $3,2 \mathrm{a}$ \\
NAV 1062 & L. pimpinellifolium & $3,1 \mathrm{a}$ \\
TWN 05/98 & L. esculentum & $3,1 \mathrm{a}$ \\
'IPA-6' & L. esculentum & $2,9 \mathrm{a}$ \\
F3(TySw5) & L. esculentum & $2,8 \mathrm{a}$ \\
F1(IAC S4-4-16A x TySw5) & L. esculentum & $2,8 \mathrm{a}$ \\
'Viradoro' & L. esculentum & $2,6 \mathrm{a}$ \\
IAC 68F 22-2-24-1 & L. esculentum x L. peruvianum & $1,8 \mathrm{~b}$ \\
PI 134417 & L. hirsutum & $1,8 \mathrm{~b}$ \\
IAC 14-2-49 & L. esculentum. x L. peruvianum $1,5 \mathrm{bc}$ \\
IAC 14-2-12+ IAC 14-2-74 & L. esculentum x L. peruvianum & $1,2 \mathrm{bc}$ \\
LA 444-1 & L. peruvianum & $1,0 \mathrm{c}$ \\
\hline Média & & 2,3 \\
C.V. (\%) & & 19,8 \\
\hline
\end{tabular}

${ }^{1}$ Escala de notas de 1 a 5 , onde $1=$ ausência de sintoma, $2=$ ligeira descoloração dos folíolos, $3=$ ligeira descoloração com início de enrugamento dos folíolos, $4=$ descoloração e enrugamento dos folíolos e $5=$ severa clorose e enrugamento acentuado dos folíolos (Matos, 2001)

${ }^{2}$ Médias seguidas de mesma letra na coluna não diferem entre si ao nível de 5\% de significância pelo teste Tukey.

de-tomateiro Tuta absoluta (Meyrick) (Lourenção et al., 1984), constituindo-se em germoplasma de valor para uso em melhoramento do tomateiro. Dentre todos os genótipos testados, uma planta do híbrido $\mathrm{F}_{1}$ (IAC S4-4-16A x TySw5) apresentou excelente vigor durante o seu desenvolvimento pós-transplante e ausência de sintomas da geminivirose. Esta planta foi transplantada para vaso visando confirmar posteriormente, a resistência ao geminivírus nas gerações subseqüentes (progênies). Os demais genótipos que compuseram o experimento não diferiram entre si, apresentando variação de 2,6 a 3,2 na intensidade de sintomas. Neste grupo ficaram as cultivares IPA-6 e Viradoro, os genótipos $\mathrm{F}_{1}$ (IAC S4-3-18C x TySw5), TWN 05/98, $\mathrm{F}_{3}$ (TySw5), F (IAC S4-4-16A x TySw5) e NAV 1062, pertencente à espécie selvagem $L$. pimpinellifolium. Neste experimento sobressaíram-se três populações derivadas de hibridações interespecíficas com L. peruvianum (duas delas com um retrocruzamento para L. esculentum - série IAC 142) como os mais promissores para utilização nos programas de melhoramento genético do tomateiro para resistência a geminivírus. Dentro deste grupo, estão as linhagens PI 134417 (L. hirsutum) e LA 444-1 (L. peruvianum), sendo que esta última recebeu nota 1,0 para todas as plantas avaliadas.

Não se conhece a herança da resistência das populações derivadas de L. peruvianum utilizadas neste trabalho. Conforme já discutido, o emprego de novas fontes de resistência, principalmente aquelas de genealogias mais distantes, como a população IAC 14-2, reveste-se de muita importância devido à variabilidade de isolados de geminivírus existentes dentro e fora do país.

\section{Avaliação em gaiolas}

Nos testes em gaiolas ( $1^{\circ}$ experimento, Tabela 3$)$, a testemunha 'IPA-6' apresentou suscetibilidade ao isolado de geminivírus com média de severidade de sintomas muito próxima da nota máxima, confirmando resultados obtidos em telado (Tabela 2). Observou-se também um grupo de genótipos que pode ser considerado intermediário quanto à resistência ao geminivírus, ainda em segregação para o gene dominante Ty-1: $\mathrm{F}_{1}$ (TPN B 51099 x TySw5), $\mathrm{F}_{2}$ (TWN 02/98 x TySw5), $\mathrm{F}_{2}$ (TWN 05/98 x Gem Pride), com valores médios de notas entre 2,2 e 2,4. As populações sob seleção, $\mathrm{F}_{4}$ (TySw5) e IAC 14-2-49, esta última derivada de $L$. peruvianum, constituíram o grupo com maior grau de resistência. Torna-se relevante continuar os testes de avaliação precoce das progênies de plantas selecionadas para fixação da resistência ao geminivírus e, posteriormente, para caracteres comerciais de tomate industrial e de mesa.

O uso de garrafas transparentes com os insetos vetores mostrou-se adequado para discriminação rápida (28 dias) de genótipos quanto à resistência ao geminivírus. Este teste, com plântulas apresentando de quatro a seis folhas verdadeiras, facilita muito a seleção rápida de genótipos em segregação para fins de melhoramento genético, pois pode-se trabalhar com muitos tratamentos espaçados no tempo, além de possibilitar a utilização de diferentes densidades populacionais de mosca-branca para melhor avaliação da resistência.

No segundo experimento, também do tipo confinado e com as mesmas variáveis do experimento anterior, a testemunha 'IPA-6' mostrou-se novamente como a mais suscetível (nota 4,4), embora não diferindo dos cruzamentos $\mathrm{F}_{2}$ (TX-414 x Rey de los Tempranos) e de NAV 1062 ( $L$. pimpinellifolium), com notas de 4,1 e 3,3, respectivamente, quanto à severidade de sintomas de geminivírus nas plantas (Tabela 3). Num grupo intermediário, com nota média 2,1, ficaram $\mathrm{F}_{3}$ (IAC S4-4-16A x Gem Pride) e a linhagem de $L$. hirsutum, PI 134417. Com praticamente ausência de sintomas e diferindo de todos os demais tratamentos, com nota média ao redor de 1,0, situaram-se a linhagem LA 444-1 e o híbrido 'Franco'. Assim como 'Densus', este híbrido mostrou-se altamente resistente ao isolado de geminivírus utilizado no presente estudo. As plantas de 'Franco' apresentaram excelente vigor e frutos grandes, tipo salada e de crescimento indeterminado. Cruzamentos destes genótipos, especialmente 'Franco', pelo seu ótimo vigor, com os genótipos IAC S4-416A e IAC S4-3-18C, ambos resistentes a tospovírus, já estão em andamento, visando incorporar resistência aos dois grupos de vírus numa mesma cultivar. Também se deve ressaltar a necessidade de avaliação do comportamento dos híbridos 'Franco' e 'Densus' em regiões e épocas de alta incidência de geminivírus, como vem ocorrendo freqüentemente em várias localidades paulistas e mesmo de outros estados produtores de tomate em extensas áreas, para que possa ser recomendado seu plantio com segurança. Não se tem informação precisa sobre as fontes de resistência utilizadas para a obtenção destes híbridos.

Evidencia-se, pelos resultados obtidos, que existe 
TABELA 3 - Notas médias de avaliação $^{1}$ de genótipos de tomateiro (Lycompersicon esculentum) submetidos precocemente a moscas-brancas virulíferas para resistência a geminivírus

\begin{tabular}{lcc}
\hline \hline Genótipo & Espécie & Nota $^{\mathbf{2}}$ \\
\hline Experimento 1 & & \\
'IPA-6' & Lycopersicon esculentum & $4,8 \mathrm{a}^{3}$ \\
F3(IAC S4-3-18C x TySw5) & L. esculentum & $3,5 \mathrm{ab}$ \\
F1(TPN B 51099 x TySw5) & L. esculentum & $2,4 \mathrm{~b}$ \\
F2(TWN 02/98 x TyS w5) & L. esculentum & $2,3 \mathrm{bc}$ \\
F2(TWN 05/98 x Gem Pride) & L. esculentum & $2,2 \mathrm{bc}$ \\
BX 1653088 (Densus) & L. esculentum & $1,2 \mathrm{~cd}$ \\
F4(TySw5) & L. esculentum & $1,1 \mathrm{~d}$ \\
IAC 14-2-49 & L. esculentum x L. peruvianum & $1,0 \mathrm{~d}$ \\
\hline Média & & 2,3 \\
C.V. $(\%)$ & 20,7 \\
\hline
\end{tabular}

\begin{tabular}{lcc}
\hline $\begin{array}{l}\text { Experimento 2 } \\
\text { 'IPA-6' }\end{array}$ & \\
F2(TX-414 x Rey de los Tempranos) & L. esculentum & \\
NAV 1062 & L. pimpinellifolium & $4,4 \mathrm{a}$ \\
TPN B 41099 & $4,1 \mathrm{ab}$ \\
F3(IAC S4-4-16A x Gem Pride) & $3,3 \mathrm{ab}$ \\
PI 134417 & L. esculentum & $3,0 \mathrm{bc}$ \\
'Franco' & L. hirsulentum & $2,1 \mathrm{c}$ \\
LA 444-1 & L. esculentum & $2,1 \mathrm{c}$ \\
\hline Média & L. peruvianum & $1,2 \mathrm{~d}$ \\
C.V. $(\%)$ & & $1,0 \mathrm{~d}$ \\
\hline
\end{tabular}

${ }^{1}$ Escala de notas de 1 a 5 , onde $1=$ ausência de sintoma, $2=$ ligeira descoloração dos folíolos, $3=$ ligeira descoloração com início de enrugamento dos folíolos, 4= descoloração e enrugamento dos folíolos e $5=$ severa clorose e enrugamento acentuado dos folíolos (Matos, 2001).

${ }^{2}$ Avaliação em gaiolas, 28 dias após a infestação artificial.

${ }^{3}$ Médias seguidas de mesma letra na coluna não diferem entre si ao nível de 5\% de significância pelo teste Tukey.

variabilidade genética dentro de Lycopersicon para resistência a TYVSV, havendo inclusive material comercial ('Franco' e 'Densus') resistente ao isolado testado. Linhagens selvagens, como LA 444-1 (L. peruvianum) e PI 134417 (L. hirsutum) e populações de origem interespecíficas (série IAC 14-2) apresentam níveis variáveis de resistência, constituindo-se em germoplasma de valor para melhoramento genético, uma vez que também possuem resistência a outras doenças e a insetos (Lourenção et al., 1997). Ainda, o método de avaliação de resistência em plântulas, sob condições de confinamento (gaiolas), mostrou-se adequado para discriminar precocemente genótipos quanto à reação ao geminivírus.

\section{REFERÊNCIAS BIBLIOGRÁFICAS}

BELÉN PICÓ, M.J.D. \& NUEZ, F. Evaluation of whitefly-mediated inoculation techniques to screen Lycopersicon esculentum and wild relatives for resistance to "Tomato yellow leaf curl virus". Euphytica 101:259-271. 1998.

BEZERRA, I.C., LIMA, M.F., RIBEIRO, S.G., GIORDANO, L.B., ZERBINI, F.M. \& ÁVILA, A.C. Occurrence of geminivirus in tomato producing areas in Submédio São Francisco. Fitopatologia Brasileira 22:331. 1997. (Resumo).

BROWN, J.K., FROHLICH, D.R. \& ROSELL, R.C. The sweetpotato or silverleaf whiteflies: biotypes of Bemisia tabaci or a species complex? Annual Review of Entomology 40:511-534. 1995a.
BROWN, J.K., COATS, S.A., BEDFORD, I.D., MARKHAM, P.G., BIRD, J. \& FROHLICH, D.R. Characterization and distribution of esterase electromorphs in the whitefly, Bemisia tabaci (Genn.) (Homoptera: Aleyrodidae). Biochemical Genetics 33:205-214. 1995 b.

FARIA, J.C., SOUZA-DIAS, J.A.C., SLACK, S.A. \& MAXWELL, D.P. A new geminivirus associated with tomato in the State of São Paulo, Brazil. Plant Disease 81:423. 1997. (Note)

FERREIRA, P.T.O., BEZERRA, I.C., VILLAS BÔAS, G.L., RIBEIRO, S.G. \& GIORDANO, L.B. Avaliação de fontes de resistência a isolado de geminivírus com genoma bipartido transmitido por Bemisia argentifolli em Lycopersicon spp. Fitopatologia Brasileira 24:131-135. 1999.

GERLING, D. Whiteflies: their bionomics, pest status, and management. Intercept, England. 1990.

GIORDANO, L.B., BOITEUX, L.S. \& HORINO, H. Avaliações em condições de campo de genótipos de tomate para a resistência a tospoviroses. Horticultura Brasileira 13:28-31. 1994.

GIORDANO, L.B., BEZERRA, I.C., FERRAZ, E., ÁVILA, AC., LIMA, M.F., RESENDE, L.V. \& SOUZA, A.J. Desenvolvimento de linhagens e cultivares de tomateiro para o Nordeste do Brasil com resistência a tospoviroses e geminiviroses. In: Queiroz, M.A., Goedbert, C.O., Ramos, S.R.R. (Ed.) Recursos Genéticos e Melhoramento de Plantas para o Nordeste Brasileiro. (on line). Petrolina. Embrapa Semi-Árido, 1999. Disponível via www - htpp:/ /www.cpatsa.embrapa.br

HARRISON, B.D. Advances in geminivirus research. Annual Review of Phytopathology 23:55-82. 1985.

HUNTER, W.B., HIEBERT, E., WEBB, S.E., TSAI, J.H. \& POSTON, J.E.L. Location of geminiviruses in the whitefly Bemisia tabaci (Homoptera: Aleyrodidae). Plant Disease 82:1147-1151. 1998.

KASRAWI, M.A., SUWWAN, M.A. \& MANSOUR, A. Sources of resistance to Tomato yellow leaf curl virus (TYLCV) in Lycopersicon species. Euphytica 37:61-64. 1988.

LATERROT, H. Present state of the genetic control of Tomato yellow leaf curl virus and of the EEC-supported breeding programme. In: Stamova, L. (Ed.), Eucarpia Tomato-93. Proceedings XII th Eucarpia Meeting on Tomato Genetics and Breeding, Bulgaria, 1993. pp.1924.

LATERROT, H. Breeding network to create tomato varieties resistant to tomato yellow leaf curl virus (TYLCV). Fruits 50:439-444. 1995.

LOURENÇÃO, A.L., NAGAI, H. \& ZULLO, M.A.T. Fontes de resistência a Scrobipalpula absoluta (Meyrick, 1917) em tomateiro. Bragantia 43:569-577. 1984.

LOURENÇÃO, A.L., NAGAI, H., SIQUEIRA, W.J., USBERTI FILHO, J.A. \& MELO, A.M.T. Seleção de tomateiros resistentes a tospovírus. Bragantia 56:21-31. 1997.

LOURENÇÃO, A.L., SIQUEIRA, W.J., MELO, A.M.T., MELO, P.C.T., COLARICCIO, A., FONTE, L.C. \& CHAVES, A.L.R. Avaliação da resistência a tospovírus em cultivares e linhagens de tomateiro. Summa Phytopathologica 27:17-23. 2001.

MATOS, E.S. Avaliação de tomateiro para resistência a tospovírus e geminivírus. (Dissertação de mestrado). Campinas, Instituto Agronômico (IAC). 2001. 83p.

MICHELSON, I., ZAMIR, D. \& CZOSNEK, H. Accumulation and translocation of tomato yellow leaf curl virus (TYLCV) in a Lycopersicon esculentum breeding line containing the $L$. chilense 
Resistência de genótipos de tomateiro a um isolado de geminivírus...

TYLCV tolerance gene Ty-1. Phytopathology 84:928-933. 1994.

PALMER, K.E. \& RYBICKI, E.P. The molecular biology of mastreviruses. Advances in Virus Research 50:183-234. 1998.

PILOWSKY, M. \& COHEN, S. Inheritance of resistance to tomato yellow leaf curl virus in tomatoes. Phytopathology 64:632-635. 1974.

PILOWSKY, M. \& COHEN, S. Tolerance to tomato yellow leaf curl virus derived from Lycopersicon peruvianum. Plant Disease 74:248-250. 1990.

REZENDE, E.A., FILGUEIRA, F.A.R., ZERBINI, F.M., MACIELZAMBOLIM, E., FERNANDES, J.J. \& GILBERTSON, R.L. Tomato infected with geminivirus in greenhouse conditions at Uberlândia - MG, Brazil. Fitopatologia Brasileira 21:424. 1996. (Resumo).

RIBEIRO, S.G., MELO, L.V., BOITEUX, L.S., KITAJIMA, E.W. \& FARIA, J.C. Tomato infection by a geminivirus in the Federal District, Brazil. Fitopatologia Brasileira 19:330. 1994. (Resumo).

ROJAS, M.R., GILBERTSON, R.L., RUSSEL, D.R. \& MAXWELL, D.P. Use of degenerate primers in the polymerase chain reaction to detect whitefly-transmitted geminiviruses. Plant Disease 77:340-347. 1993.

ROSELL, R.C., TORREZ-JEREZ, I. \& BROWN, J.K. Tracing the geminiviruses-whitefly transmission pathway by polymerase chain reaction in whitefly extracts, saliva, hemolymph and honeydew.
Phytopathology 89:239-246. 1999.

RYBICKI, E.P. A phylogenetic and evolutionary justification for three genera of Geminiviridae. Archives of Virology 139:49-77. 1994.

TIMMERMANS, M.C., PREMDAS, O.E. \& MESSING, J. Geminiviruses and their uses as extrachromossomal replicons. Annual Review of Biochemistry and Molecular Biology 45:79112. 1994.

VAN REGENMORTEL, M.H.V., FAUQUET, C.M., BISHOP, D.H.L., CARSTENS, E., ESTES, M.K., LEMON, S., MANILOFF, J., MAYO, J.A., MCGEOCH, D.J., PRIGLE, C.R. \& WICKNER, R. Virus taxonomy: seventh report of the International Committee on the Taxonomy of Viruses. Academic Press, New York, 2000.

ZAKAY, Y., NAVOT, N., ZEIDAN, M., KEDAR, N., RABINOWITCH, H., CZOSNEK, H. \& ZAMIR, D. Screening of Lycopersicon accessions for resistance to Tomato yellow leaf curl virus: presence of viral DNA and symptom development. Plant Disease 75:279-281. 1991.

ZAMIR, D., EKSTEIN-MICHELSON, I., ZAKAY, Y., NAVOT, N., ZEIDAN, M., SARFATTI, M., ESHED, Y., HAREL, E., PLEBAN, T., van-OSS, H., KEDAR, N., RABINOWITCH, H.D. \& CZOSNEK, H. Mapping and introgression of tomato yellow leaf curl virus tolerance gene, Ty-1. Theoretical and Applied Genetics 88:141-146. 1994. 